\title{
NEW SEED SOWING TECHNIQUE AND EQUIPMENT TO RAISE LEVEL OF CROP YIELD
}

\author{
Ildar Bagautdinov, Vladimir Gryazin, Konstantin Kozlov, Vladimir Belogusev \\ Volga State University of Technology, Russia \\ bagaeldar@yandex.ru, vladimirgryazin@yandex.ru, konstantin.k-e@yandex.ru, \\ vladimir.belogusev@yandex.ru
}

\begin{abstract}
The purpose of the paper is to verify the theoretical assumption on the operability of the design of a new sowing device, which has a number of advantages in comparison with the existing ones. It is known that the shortcomings of the existing planting and sowing machines lead to considerable crop losses (uneven germination and weakened plants due to incomplete use of soil potential) and, as a consequence, losses of expensive planting materials. It is also known that the existing equipment and techniques cannot reduce the number of field vehicle movements, which leads to excessive compaction of the soil, a deterioration of its microstructure, and a decrease in fertility, as well as additional financial costs. To solve the existing problems of planting, a new technique is proposed. It is implemented on the basis of a pre-distributed planting material on a specially prepared tape. Such a technical solution allows sowing expensive planting material by the piece and in a strictly distributed sequence and, as a result, minimizing losses and ensuring a uniform depth of planting. The design of the sowing equipment is simplified and the adjusting works, as well as the cost of labour, are reduced. To confirm the theoretical assumptions, we developed a laboratory plant, and this paper presents the results of experimental work, which confirms high technological capabilities of the proposed equipment in terms of homogeneity of the seeding depth and its constructive simplicity. The presented technique based on the specially prepared tape material allows carrying out simultaneously both planting and additional agrotechnical measures, such as pointby-point application of a dosed fertilizer, which leads to an increase in the ecological compatibility of products, simultaneous soil cultivation with herbicides, etc.
\end{abstract}

Keywords: sowing equipment, planting, crop yield, seeder.

\section{Introduction}

Since ancient times, it is known that the quality of the crop depends on the quality and varietal properties of the planting material. It goes without saying that the harvest is much dependent on the care of crops. With the development of agricultural sciences and technology, it became clear that the process of sowing or planting is also very important.

According to the existing seeding technologies, it is assumed that the grain/seed is transported to the seminal duct, through which it will "gravitate" into the soil. Theoretically, this method should place seeds in a uniformly distributed row and same depth.

In practice, it turns out not quite so. First, because of the lumpy structure of the soil, a number of seeds fall deeper between the clumps or remain on the lumps themselves. As a result, we get an uneven depth of sowing. Seeds that are sowed deeper give late, and, as a rule, weak shoots. Seeds, which are not deep enough, shoot early and often undergo frost. As a result, we have about $7 \%$ of crop losses [1].

Secondly, for most machines based on the row seeding method, we also face an uneven distribution of seeds along the width of the row. That is, instead of an even distribution of the seed material over the area of feeding (the width of the seeder), we get a "mound" of seeds piled on top of each other. As a consequence, the absorption of nutrients from the soil deteriorates, a narrow row of depleted soil, on which seeds compete, and row spacing, the fertility of which is almost not used, are created $[2 ; 3]$.

This drawback is typical for cereals, which do not have wide aisles during sowing. To decrease the influence of this drawback, scatter devices are needed, which in theory should create chaotically and evenly dispersed sowing. However, in such fields it is sometimes noticeable that the grain lay unevenly: there are local condensations and sparsities.

For crops that need to be sown in one row, but must have a wide aisle, the issue of distributing seeds so that they do not interfere with each other and as much as possible use the nutrition area of the row arises.

In many works, this problem is solved with the help of a seed drill, which, in comparison with the reel one, produces a much more precise sowing [4-9]. The seed drill is a unified machine designed for 
sowing seeds of the following crops: corn, horse beans, large beans, peas, lupine, sunflower, soybean, coated beet seeds and other seeds with a minimum size of $2.5 \mathrm{~mm}$. In addition, these seeders are designed to solve the problem of unnecessary shoots, which later have to be eliminated (for example, for beets).

However, these drills have a number of disadvantages:

- high price;

- a rather complicated design requiring qualified care and maintenance;

- for pneumatic seeders, it is necessary to purchase several sets of working disks with different seeding steps;

- they cannot be applied to crops, the size of the seeds of which is small (beets, carrots, millet, etc.). This drawback can be avoided by pelleting, but this is unnecessary expenses;

- the uniformity of the seeding depth is not ensured.

Thus, it can be concluded that the existing agricultural machinery for sowing does not provide the necessary precision and uniformity of sowing, it is expensive, and therefore is inaccessible to farms, and cannot ensure an equal depth of sowing.

In addition to the aforementioned, a strong dispersion in the qualifications of the machine operators, which ensure the adjustment of agricultural machinery, leads to violations in the standards for sowing seeds and applying fertilizers. According to [10], due to violations in agricultural technology and a decrease in the level of mechanization of agriculture, Russia loses in recent years no less than $30 \%$ of the crop yield, which is only for grains of 20-25 million tons; in monetary terms, the losses are more than 100 billion rubles.

The purpose of this paper is to develop a seed sowing technology and devices that can eliminate a number of shortcomings of the existing ones.

The developed technology should have the following main advantages over the existing techniques and devices.

- For crops that require seeding in a row with a relatively large distance between plants (beets, carrots, etc.), the need for seeds decreases tens or even hundreds of times. As a result, the savings can be directed to purchase more expensive varieties.

- For crops with wide row spacing but several plants in a row (carrots, etc.), it provides an ideal distribution of seeds in a row with optimal use of the area of nutrition.

- For crops of "scattered" sowing, that is, those that should cover the aisle with a continuous cover, uniform distribution of the seeds along the space between the technological tracks is ensured.

- With the appropriate development of the technology, a sharp decrease in the number of field visits is possible, which automatically leads to an increase in the profitability of crops and a reduction in soil compaction.

- The ability to implement the developed technology dramatically reduces the number of pests in the soil.

\section{Materials and methods}

The technology developed in this article should correspond to the following parameters:

1. Use of a tape made from easily recyclable material (paper, fabric, cotton). It can be also used as a string (paper twine, thread);

2. Seeds of such planting material as beets, carrots, etc. are applied to the tapes industrially in the distributed state and by piece. For other crops, the seeds are distributed evenly across the width of the tape (according to a certain pattern);

3. When laying the tape in the soil, almost $100 \%$ of the same depth of planting is provided. If the packing is carried out, the thickness of the soil cover over the seeds will be constant;

4. The design of a seeder becomes simple, and there is no need for the adjustment of the seed volume. The sowing unit becomes rigidly connected to the seeder wheels, and there is no need to use the active drive from the tractor's power take-off shaft; 
5. After a while, the tape decomposes and is disposed naturally by turning into humus (for example, paper tape).

To confirm the calculations and theoretical assumptions on improving the quality of seeding using a belt sowing machine, we designed and manufactured a laboratory model at a scale of 1:2. The scheme of the laboratory model is shown in Fig. 1. It consists of a frame with support-drive wheels 1, the tow hitch 2 is attached to it, the reel with tape 4 and the parallelogram mechanism 5 are fixed to the frame 3 , the rode 6 connects the parallelogram mechanism 5 and the model coulter 8 , the rod 7 connects the parallelogram mechanism 5 and the baling roller 9 , and the coverer 10 is fixed on the $\operatorname{rod} 7$.

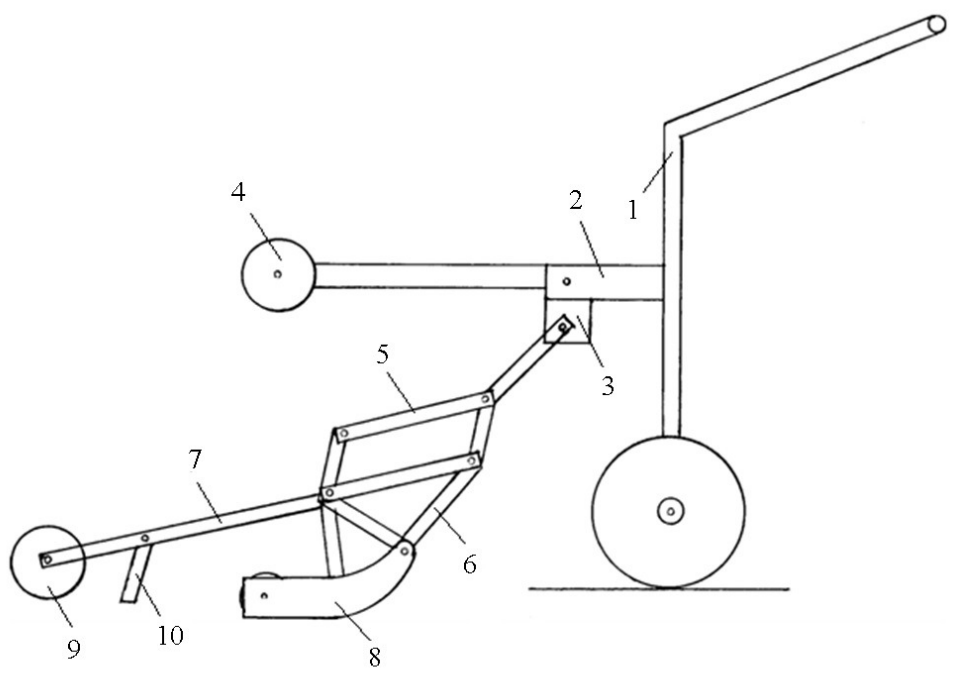

Fig. 1. Scheme of laboratory model

As a result of modelling and development of the design, we assembled a laboratory model shown in Fig. 2.

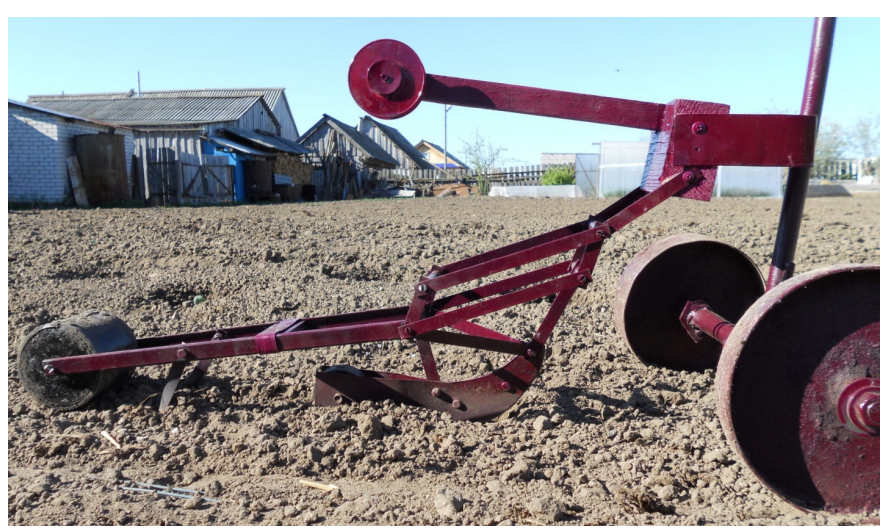

Fig. 2. Laboratory model: right view

The principle of the work of the sowing machine is to lay the tape at a given depth provided by the coulters. The tape falls into the groove created by the coulter and is covered with soil by means of the coverer and is rolled with a special wheel compacting the soil in the row area.

The experimental model of the sowing machine (Fig. 3) consists of the following main elements: wheelbarrows 1 , trailing device 2 , frame 3 , reel with tape 4, parallelogram mechanism 5 , rods 6 and 7 , coulter 8 , rolling wheel 9 , coverer 10 .

To substantiate the effectiveness of the developed seed sowing technique, two series of experiments were carried out in the present work, during which, after sowing the seeds with the help of the developed experimental model, the depth of the tape laying at various spots was measured. 


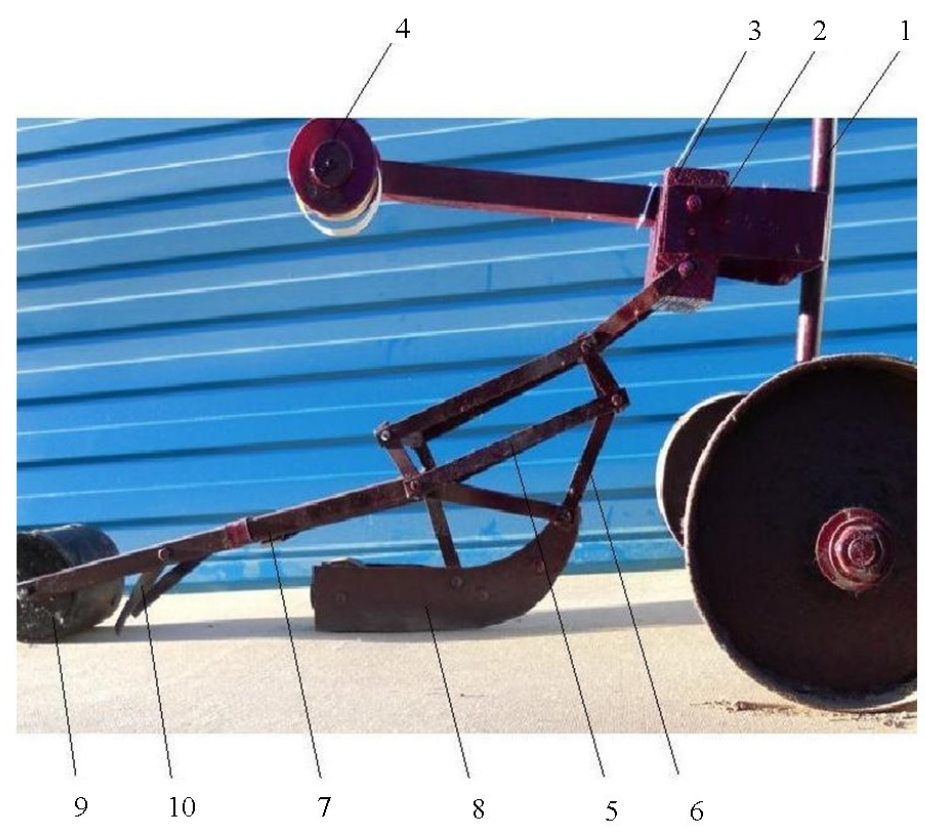

Fig. 3. Experimental sample of tape sowing machine

\section{Results and discussion}

To test the principle of the action of the sowing machine in the course of the laboratory experiment, we carried out the work of the seeder with the immersion of the tape into the soil and an assessment of its depth and uniformity of the seeding.

The experiment was carried out as follows: the experimental model was placed on the treated soil (according to the work in natural conditions); the tape was passed through a roller installed in the coulter. Then the experimental model was set in motion, the roller began to rotate pulling the tape out of the reel, and the tape was placed on the bottom of the groove, at a predetermined depth. The groove was covered with soil by means of a coverer mounted on the rods, and rolled with the wheel.

During the experiment, a theoretical assumption was set - that the tape actually fits into the soil at a given depth by the seeding machine. For the reliability and analysis of the experiment, we took photographs, which are shown in Fig. 4.

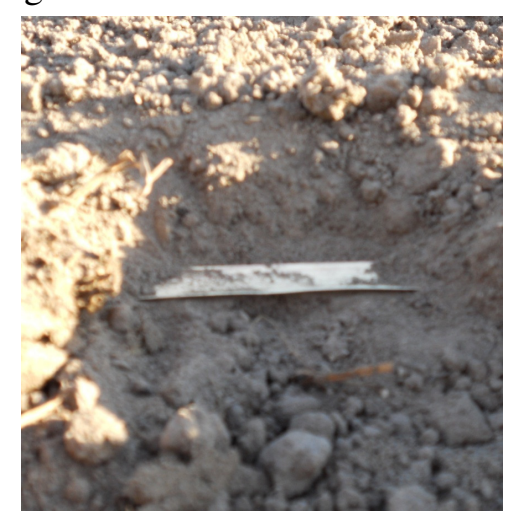

Fig. 4. Tape laid in the soil

Thus, the developed laboratory model completely simulates the process of the developed sowing machine.

After carrying out experimental studies to assess the performance of the developed sowing machine, we analysed the data obtained. During the experiment, it was necessary to assess the uniformity of the depth of the tape laying. To do this, we needed to open the seeding groove with the tape (the scheme is shown in Figure 5) in several places after a given distance. In the first experiment, 
the given depth of laying the tape was $3.25 \mathrm{~cm}$, and in the second one $-4 \mathrm{~cm}$ (Table 1). The depth of the laying was regulated by key slots located in the parallelogram mechanism.

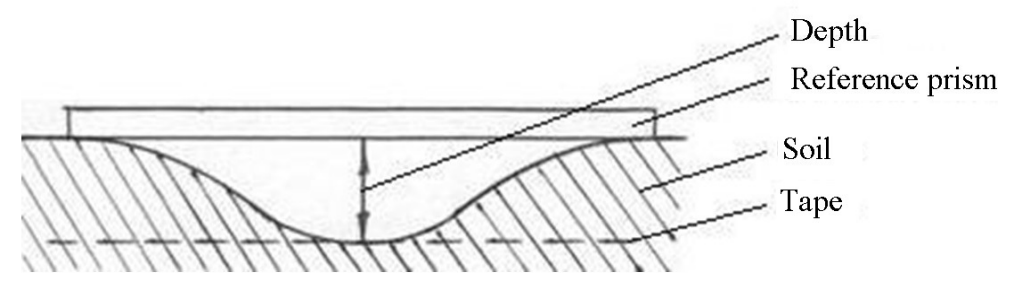

Fig. 5. Scheme for measuring depth of tape laying

Table 1

Results of measurements of the depth of the laying of the tape during the experiments

\begin{tabular}{|c|c|c|c|c|c|c|c|c|c|c|}
\hline $\begin{array}{c}\text { The distance to the places of } \\
\text { opening of the soil, m }\end{array}$ & 0.3 & 0.6 & 0.9 & 1.2 & 1.5 & 1.8 & 2.1 & 2.4 & 2.7 & 3.0 \\
\hline The first experiment, cm & 3.5 & 3.3 & 3.4 & 3.4 & 3.2 & 3.3 & 3.2 & 3.1 & 3.3 & 3.4 \\
\hline The second experiment, cm & 4.1 & 4.0 & 4.1 & 4.2 & 4.3 & 4.2 & 4.2 & 4.1 & 4.0 & 4.1 \\
\hline
\end{tabular}

Figure 6 shows the graphical dependence of the depth of laying along the plowed field.

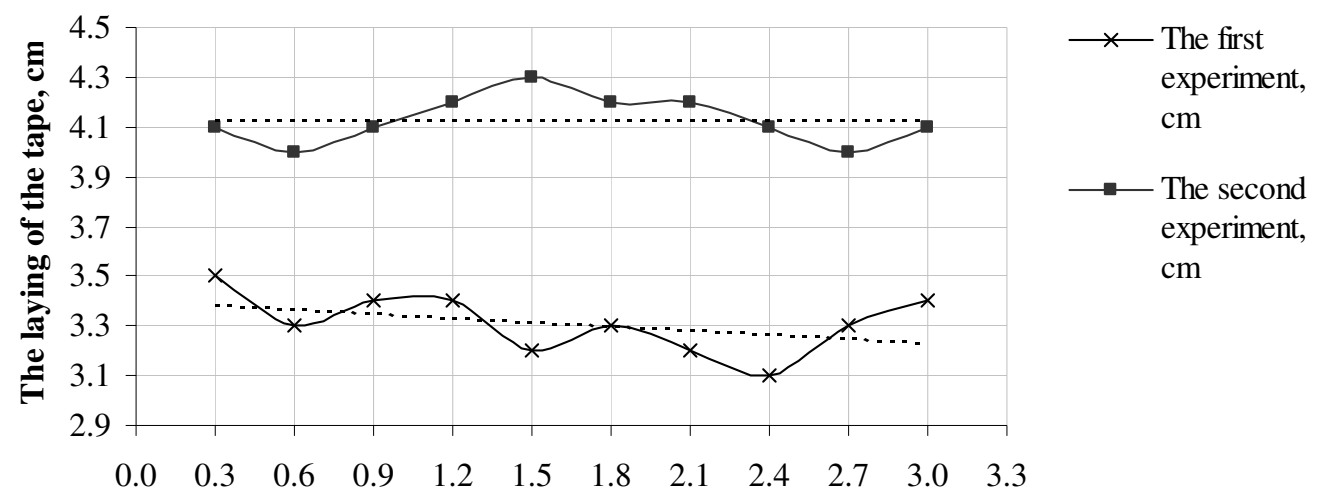

The distance to the places of opening of the soil, $\mathbf{m}$

Fig. 6. Dependence of the depth of laying along the plowed field

According to the data obtained in the first experiment, the spread of the values of the preset laying depth of the tape was $1.85 \%$ and in the second experiment the spread was $3.25 \%$, which indicates the complete operability of the designed unit and the reliability of the proposed technique.

The experimental model of a sowing machine is functional and can be recommended for the production of a full-size model for the further experimental work.

From the pre-distributed technology of sowing, a number of favourable features arise, which is difficult to obtain for one pass using other technologies. Let us consider them in more detail.

1. Seeds can be "glued" with a hygroscopic jelly, impregnated with trace elements and fertilizers, sufficient for initial germination. This will increase the germination, and jelly attracts soil moisture. In this case, the pointed delivery of fertilizers is provided directly to the roots of plants without "spreading over the areas."

2. The tape can be impregnated with soil herbicides, insecticides, fungicides, zoocides in a certain optimal volume;

3. Impregnation of the tape with fertilizers and preparations against pests allow you not to add them in addition, reduce trampling of the soil and the number of trips to the field;

4. The tape laid under the soil does not let the weeds grow under it; 
5. The tape can be wider than the crop sowing strip, then the edges of the tape that are beyond the edge of the strip and impregnated with herbicides and fungicides will destroy the weeds and fungi in the inter-rows, providing additional cleaning of the field. In addition, the tape, as already mentioned, mechanically interferes with the germination of weeds;

6. Using a non-uniform tape, so that the tape in the row-to-row is denser (with specified properties) than in the planting strips, prevents the loss of soil moisture, thereby improving the growing conditions of the cultivated crops.

7. Theoretically, if the tape is made netlike, then it is possible to reel the net to harvest the root crops.

\section{Conclusions}

According to the conducted researches and the received results it is possible to conclude that the technique of sowing and technology of preparation of seeds will allow reducing considerably the volume of expenses for production of the crops. If the distance between the seeds is not required, it is still possible to scatter the seeds evenly with a certain step, for example, for carrots. This will reduce competition between the plants and allow efficient use of the soil potential.

If you strictly adhere to the conditions of sowing, then you can make it so that the rows will be not only longitudinal, but also transverse - hence, you can cultivate across the rows. Then they can be earthed up without hand labour.

The technique and technology of applying seeds to a tape can be used for a large area, rather than for a single farm, since the preparation of tapes (cords, threads) may well be carried out during the cold season.

However, the proposed technology has a drawback connected with the large size of the roll with the tape. In order to solve this problem, we propose a carrier cord, to which the seeds are attached. Then the cord can be wound like a wire in transformers.

\section{References}

[1] Heege H.J. Die Kornverteilung der Getreidebestellung. Landtechnik, 1974, No 5, pp. 210-213. (In German).

[2] Тускаев Т.P. Management of the technical potential of agricultural production (Управление техническим потенциалом сельскохозяйственного производства). Moscow: ГУП «Агропрогресс», 2002. 188 p. (In Russian).

[3] Тускаев T.P. Economic strategy of development and use of the technical potential of agriculture (Экономическая стратегия развития и использования технического потенциала сельского хозяйства). Moscow: ГУП «Агропрогресс», 2001. 190 p. (In Russian).

[4] Sharipov G.M., Paraforos D.S., Pulatov A.S. etc. Dynamic performance of a no-till seeding assembly. Biosystems Engineering, vol. 158, 2017, pp. 64-75.

[5] Nielsen S.K., Munkholm L.J., Lamandé M. etc. Seed drill depth control system for precision seeding. Computers and Electronics in Agriculture, vol. 144, 2018, pp. 174-180.

[6] Pandia O., Saracin I., Bozga I. etc. Studies Regarding Pneumatic Equipment for Sowing Small Seeds in Cups. 1. Agriculture and Agricultural Science Procedia, vol. 6, 2015, pp. 690-695.

[7] Yatskul A., Lemiere J.-P., Cointault F. Influence of the divider head functioning conditions and geometry on the seed's distribution accuracy of the air-seeder. Biosystems Engineering, vol. 161, 2017, pp. 120-134.

[8] Shepelev S., Shepelev V., Almetova Z. Optimization of Technical Equipment for Crop Sowing Processes. Procedia Engineering, vol. 150, 2016, pp. 1258-1262.

[9] Sidhu H.S., Singh M., Singh Y. etc. Development and evaluation of the Turbo Happy Seeder for sowing wheat into heavy rice residues in NW India. Field Crops Research, vol. 184, 2015, pp. 201-212.

[10] Тускаев Т.P. Technical equipment of agriculture and problems of restoration of the agroindustrial complex (Техническая оснащенность сельского хозяйства и проблемы восстановления агропромышленного комплекса). Gorsky State Agrarian University: Горский государственный аграрный университет, 2009. (In Russian). 